\title{
BASM's new wave
}

The 1991 Annual Meeting of BASM in the glorious surroundings of the English Lake District was a triumph for the organizing committee but, more significantly, heralded a resurgence of the new BASM.

For the seasoned observer a number of subtle changes were apparent - more and better academic sessions, more commercial support and more committed members enjoying even more entertainment. The visiting delegates of the N.W. Europe Chapter of FIMS whom BASM hosted were a popular bonus which tokens well for the development of our own area in the world organization.

If the physician's finger can detect fine pulses, then the subtle change this year was the emergence of an identifiable block of active members carrying the banners of sports medicine. Gone the days of elderly tourists clocking up postgraduate allowances. The impetus now comes from a swelling corps of our own graduates - 'our own' meaning that core of BASM course recidivists plus the new graduates from the London Hospital, the London Institute and the Apothecaries and Scottish exams. Suddenly, 'non-existent' British sports medicine has generated its own critical mass and this cadre is rapidly taking over BASM and will rightly be putting pressure on the officers to toe a much more active and aggressive line than previously. This, in turn, is the moment the officers have been waiting for. In such a climate of robust assertion we should find the energy and support for the goals we have long pursued - summarized in the single word 'professionalism'.

At a difficult time when the Sports Council's prevarications and financial insecurity have delayed the foundation of the National Sports Medicine Institute to a deplorable extent, it is imperative that the body of the BASM membership should keep a close scrutiny on this development. It should be aware that not all factions wish BASM all that well and that it is now advantageous that BASM can speak from a position of strength. It is the main organizer of courses, the only membership organization, the internationally affiliated and recognized representative body and the only journal publisher in this area. It has initiated clinic registration with a view to comprehensive validations in due course. BASM should guard against the smash-and-grab raids for these assets which any NSMI might be tempted to contemplate upon all organizations with services or assets which a central agency might covet.

To this end, and bearing in mind that a cooperative working relationship will have to be struck between BASM and other parties and the NSMI, it is essential that BASM now disciplines its growing strength and identifies clearly where its interests and commitments are to lie in the next few years.

At present, so far as can be seen, the NSMI is flexible and hopelessly underfunded. It will have to identify its policy and priorities and then see how it can achieve each of them - perhaps mostly in partnership with other professional organizations. It behoves BASM to have its own catalogue ready for an early call on the new Institute. 